\title{
Semantic coercion: Rethinking motion verbs in Thinking-For-Speaking
}

\author{
Dr. Imed Louhichi \\ Assistant Professor\& Chair \\ American University of Ras Al Khaimah \\ U.A.E.
}

\begin{abstract}
The categorization of motion verbs in THINKING-FOR-SPEAKING (TfS) research paradigm entails some theoretical problems that need to be addressed. This conclusion is motivated by the examination of motion verb types listed in Berman \&Slobin (1994, p. 198) for Spanish and English narrators of 'the frog story' (Mayer, 1969). These lists show a range of semantically different verb types including verbs describing MANNER VIA MOTION (e.g., climb), CAUSE VIA MOTION (e.g., push), PATH VIA MOTION (e.g., come), SOUND-EMISSION (e.g., buzz), and ACTION (e.g., knock). We argue that in the absence of any clear theoretical framework for why, how and whether these verbs should be categorized as motion verbs, TfS research runs the risk of slipping into inconsistency.
\end{abstract}

To this end, interdisciplinary insights about the behavior of motion verbs in English suggest that SEMANTIC COERCIONthe process whereby non-motion verbs are coerced into the expression of motion meanings - merits more attention in TfS research than it currently receives. The notion of MOTIONIZATIONis offered as a first step in this direction.

\section{Introduction}

\subsection{Background: Motion event typology in grammar and discourse}

Talmy $(1985,2000)$ demonstrates that languages can be classified according to where in a clause the semantic components PATH versus MANNER are usually lexicalized. If path is encoded in the main verb and manner is expressed in adjuncts or subordinate clauses, then this language is said to be VERB-FRAMED (V-language). Alternatively, if path is encoded in a SATELLITE - a spatial particle that accompanies the main verb - and manner is conflated (fused) with MOTION in the main verb, then this language is said to be SATELLITE-FRAMED(S-language). ${ }^{1}$

Crucially, Talmy (1985) argues that the preferred lexicalization patterns of either type of language have important consequences for how motion is treated in these languages. This claim has raised several questions for discourseorientated researchers. One such question is whether the lexicalization patterns inherent in V-languages and Slanguages can influence how speakers habitually attend to and talk about motion events. With this question in mind, Berman \&Slobin (1994) and their collaborators compared the discourse behaviors of L1 speakers of typologically different languages based on various discourse genres. ${ }^{2}$ They have identified several parameters of possible variations in the narrative behavior of S-and V-language speakers, one of which is what we call in the remainder of this article THE MOTION VERB PARAMETER (MvP).

The MvP involves the comparison of the number, quality, and types of motion verbs. We focus on this parameter for several reasons. First, the MvP plays a key role in situating languages within Talmy's binary typology. Second, the thinking-for-speaking (TfS) hypothesis (Slobin 1987, 1996a, 2000, 2008) claims that linguistic categories influence thought processes while in the act of speaking (Slobin, 1987, p. 435) and the MvP is often used as a yardstick to validate or refute this proposal. Third, many studies adopting Berman \&Slobin's (1994) research paradigm have barely attempted to question the theoretical and empirical underpinnings of the MvP, and in this way, many have left fundamental questions like 'what motion verbs are' and 'whether motion verbs are classified equally crosstypologically' open to individual interpretations. The next section develops these thoughts further. We show that the status of motion verbs in TfS research is controversial and that addressing this issue fills an important knowledge gap within the TfS research paradigm.

\footnotetext{
${ }^{1}$ Slobin (2004) has proposed equipollent-framed languages as a third member to this typology. We overlook this type here for two reasons. First, it is not clear at this stage how the inclusion of this type serves the aim of this paper. Second, Talmy (2009) has raised objections against Slobin's (2004) proposal.

${ }^{2}$ E.g., Storytelling using the picture book 'Frog, where are you?' (Mayer, 1969), newspaper articles, and translation materials. 


\subsection{Rationale and outline}

Research into the linguistic conceptualization of motion has always thrived upon the assumption that motion verbs form a unified class with necessary and sufficient conditions for membership. Yet, a fundamental question that emerges from both Talmy's $(1985,2000)$ motion event typology and Slobin's (1996b) TfS discourse typology is how to identify and classify motion verbs.

Support for this line of criticism may be evidenced in TfS studies. For instance, in a study comparing the narratives of English and Spanish speakers, Berman and Slobin (1994, p. 198) identified 45 motion verbs in the English data and 29 in the Spanish: ${ }^{3}$

(1) (a) English motion verbs: (Slobin, 1996b, p. 198)

buck, depart, buzz, carry, come, bump, splash, chase, dump, escape, climb, splat, knock, drop, follow, creep, hide, push, head, crawl, throw, land, fall, take, leave, float, tip, get, fly, make.fall, go, hop, move, jump, limp, plummet, pop, rush, run, slip, sneak, swoop, tumble, walk, wander. ${ }^{4}$

(1) (b) Spanish Motion verbs (Slobin, 1996b, 198)

perseguir 'chase', venir 'come', saltar 'jump', arrojar 'throw', ir (se) 'go', nadar 'swim', meter-se 'insert oneself', bajar 'descend', volar(se) 'fly away', poner-se 'put oneself', acercarse 'approach', caer(se) 'fall', dar-un-empujón'push', sacar-se 'remove oneself/exit', caer(se) 'fall', hacercaer 'make fall', salir 'exit', huir 'flee', llevar(se) 'carry', entrar 'enter', escaper 'escape', tirar 'throw', llegar 'arrive', regresar 'return', vover(se) 'return', traspasar 'go over', subir(se) 'ascend', marchar(se) 'go', alcanzar'reach'.

As in the literature, the verbs in (1a) and (1b) have been listed quite randomly and without any explicit discussion of their semantics or a clear rationale for their classification as motion verbs. On closer inspection, these verbs can be classified according to five semantic notions and conflation patterns, namely: MANNER VIA MOTION (e.g., climb), CAUSE VIA MOTION (e.g.,push), PATH VIA MOTION (e.g.,come), SOUND-EMISSION (e.g.,buzz), and ACTION (e.g.,knock). Table 2 reproduces the verbs in Table 1 accordingly:

Table 1: Categorization of English Motion Verbs (Adapted from Slobin, 1996b, p. 198)

\begin{tabular}{|c|c|c|}
\hline $\begin{array}{l}\text { CONFLATION } \\
\text { PATTERNS } \\
\end{array}$ & ENGLISH & SPANISH \\
\hline $\begin{array}{l}\text { MOTION } \\
\quad+ \\
\text { MANNER }\end{array}$ & $\begin{array}{l}\text { fly, buck, bump, climb, creep, } \\
\text { crawl, fall, float, plummet, hop, } \\
\text { jump, limp, pop, rush, run, slip, } \\
\text { sneak, swoop, tumble, walk, } \\
\text { wander }\end{array}$ & $\begin{array}{l}\text { nadar 'swim', volar(se) 'fly away', } \\
\text { caer(se) 'fall', huir 'flee' }\end{array}$ \\
\hline $\begin{array}{l}\text { MOTION + } \\
\text { SOUND-EMISSION }\end{array}$ & buzz, splash, splat & - \\
\hline ACTION $^{5}$ & knock, hide & - \\
\hline $\begin{array}{l}\text { MOTION } \\
+ \\
\text { CAUSE }\end{array}$ & $\begin{array}{l}\text { carry, chase, drop, dump, } \\
\text { make.fall, push, throw, take, tip }\end{array}$ & $\begin{array}{l}\text { arrojar 'throw', meter-se 'insert oneself', poner-se 'put } \\
\text { oneself', dar-un-empujón 'push', hacercaer 'make.fall', } \\
\text { llevar(se) 'carry', perseguir 'chase', tirar 'throw' }\end{array}$ \\
\hline $\begin{array}{l}\text { MOTION } \\
+ \\
\text { PATH }\end{array}$ & $\begin{array}{l}\text { depart, come, escape, follow, } \\
\text { head, leave, get, go, move, land }\end{array}$ & $\begin{array}{l}\text { venir 'come', acercarse 'approach', bajar 'descend', } \\
\text { sacar-se 'remove oneself, exit', salir' exit', entrar' enter', } \\
\text { escapar 'escape', llegar 'arrive', regresar 'return', } \\
\text { vover(se) 'return', traspasar 'go over', subir(se) 'ascend', } \\
\text { marchar(se) 'go', alcanzar 'reach' }\end{array}$ \\
\hline
\end{tabular}

Table 1 shows that verbs expressing sound-emission (e.g.,splat, splash, and buzz) and action (e.g.,Knock) have been listed for the English and not for the Spanish. This is significant in two respects.

\footnotetext{
${ }^{3}$ The lists and the classification reflect solely the verbs found in Berman \&Slobin's (1994) corpora.

${ }^{4}$ The dot in make.fall suggests that the semantic components [CAUSE + MOTION] are conflated in a single word form.

${ }^{5} \mathrm{We}$ use this semantic notion as a general category that is capable of accommodating all atypical verbs that we cannot assign to the other four categories in Table 1.
} 
First in terms of the MvP, it is important to discuss the semantics of these verbs in order to justify the inclusion of sound-emission and action verbs into the motion verb data set. Second, it is important to address the question of why the English have opted for the verbs in question but the Spanish have not.

Insights into the first query may be gained from a review of theTfS literature . For instance, according to Ibarretxe Antuñano (2004, p. 322) "[t]he first step that Slobin takes in his analysis of the typological frame of motion events is to look at the entire collection of motion verbs - both cause and self-movement - used in the Frog Stories".

Equally, according to Caballero (2007) verbs of change of state (unfold, stretch, or unfurl) and verbs expressing 'contact by impact' (e.g.,kick and punch) should be classed as motion verbs, as long as they adhere to one of two factors or both: (a) these verbs "are characterized by the fact that 'motion' is also part and parcel of their semantics irrespective of whether this is the core meaning or conflates with other notions" (Caballero, 2007, p. 2101); (b) such verbs "occur with motion particles [...] which turn them into motion verbs proper" (Caballero, 2007, 2101).

Additional hints about the categorization of motion verbs in TfSmay be gleaned from Berman and Slobin's writings. For instance, in the analysis of The cliff scene, Slobin (1996b, p. 200) mentions that "whether the verb occurred alone or with some kind of locative addition - a particle, prepositional phrase, or adverbial expression indicating downward direction, source, or goal of motion" were taken into account. He further adds that although the analysis of motion events has been extended "from verbs of motion to include associated locativephrases, have gone from individual motion verbs to series of clauses, the focus has remainedon descriptions of movement" (1996b, p. 204). More importantly, when discussing the use of spatial particles in the frog stories, Berman \&Slobin have observed that "locative particles add a directional element to motion verbs - as in go in, climb up, swim over (1994, p. 156)", as well as "nonmotion activity verbs, both transitive and intransitive" (1994, p. 159).

Insightful as Berman \&Slobin's (1994), Slobin's (1996b), Ibarretxe-Antuñano's (2004), and Caballero's (2007) definitional criteria may be, they lack in-depth theoretical discussion of why it is acceptable to (a) stretch the semantics of non-motion verbs in such a way that it fits within the MvP in S-framed languages and (b) whether the same semantic phenomenon that is functional in S-languages is equally functional in V-languages.

In fact, concerns over lack of clarity in the study of motion verbs at both the theoretical and the methodological levels have been echoed in the literature. For instance, according to Levin (1993, p. 15) the assumption that English motion verbs form a homogeneous class is fundamentally flawed because a closer examination of the syntactic behavior of this class of verbs reveals there is not a single syntactic feature common to all. Similarly, according to Zlatev\&Yanglang (2004, p. 162) "[w]ork in motion event typology [...] has been hampered by a lack of clear definition" of what motion verbs are. They claimTalmy (1985) is "somewhat to blame for this" since in this highly influential paper, "terminological issues were left unclear" (2004, p. 162), and that even the category of manner is left "ill-defined" (2004, p. 163). Ibarretxe-Antuñano (2015) has also raised concerns about the fuzzy nature of the MvP in TfS. She points out that researchers often assume two clear-cut subclasses of motion verbs: "path only" and "manner only". She claims this is wrong since the borderline between the two is fuzzy. Perhaps, what is even more telling is that Slobin (2006) has explicitly expressed his reluctance to address definitional issues when it comes to manner of motion verbs. He states "Talmy provides no clear definition of manner nor is there one to be offered here" (2006, p. 3).

With these theoretical and methodological concerns in mind, in what follows we seek insights from scholars whose theoretical backgrounds and orientations are as different as generative grammar, developmental psychology, and usagebased approaches to semantic and grammatical analysis. The main goal is to showcase difficulties inherent in the MvP that have not been given enough recognition in the TfS research paradigm but have long been known to non-TfS literature. We discuss these difficulties with reference to the notion of SEMANTICCOERCION.

Semantic coercion provides a valid working hypothesis becauseit has often been used to explain issues of "grammatical and semantic incongruity" (Ziegeler, 2007, p. 992). Consequently, to the extent that coercion offers a viable framework for "the resolution of mismatch" (Ziegeler, 2007, p. 992), it promises to be a fertile ground in which discrepancies associated with the MvP can be understood. ${ }^{6}$

\footnotetext{
${ }^{6}$ Due to space contraints, this paper will not offer a comprehensive discussion of how various scholars have used coercion to explain different phenomena at the syntax-semantic interface. Whether 'nominal', 'aspectual', or 'complement' coercion, some kind of a mismatch between a head word, its syntactic environment (i.e., selectional restrictions), and its semantics is at stake. What seems to be a point of disagreement between the various approaches to coercion is where scholars are willing to position themselves on the 'pragmatic' versus 'syntactic' pendulum. In top-down theories of meaning construction the pendulum swings in favor of the latter as syntax is considered "pre-determined and immutable" (e.g., Nichaelis, 2003, 2004; cited in Ziegeler, 2007, p. 994). However, for those who believe in bottom-up processes (e.g., Dowty, 1986; cited in Ziegeler, 2007, p. 997 and Levinson, 2000, p. 246; cited in Ziegeler 2007, p. 1001) the pendulum swings in favor of the 94
} 
The outline to this article is as follows. In Section 2, we discuss whether PERCEPTION verbs (e.g.,look, see) ought to be classified as motion verbs in TfS research. This will include perspectives from generative grammar (Gruber, 1967), developmental psychology (Landau \&Gleitman, 1985) and typological research (Talmy, 2000;Slobin, 2008). In Section 3, we extend this discussion to cover SOUND-EMISSION verbs based on Levin (1993). In Section 4, we include other types and tokens of non-motion verbs based on Goldberg's (1995) CAUSED-MOTIONCONSTRUCTION.

To anticipate, all evidence suggest that two-tiered constructions consisting of a verb and a path-bearing phrase yield a motional reading regardless of the primary semantics of the verb. This conclusion warrants a discussion of two points. First, whether 'plausibility' (Ziegeler, 2007) and 'native speaker judgment' (Slobin, 2008) can be used as valid constraints on the classification (Section 5.1). Second, based on a V-language like Farsi (Feiz, 2011), we raise the point that semantic coercion may manifest itself differently in V-languages and S-languages (Section 5.2). These arguments pave the way for the introduction of MOTIONIZATION (Louhichi, 2015) - a proposal that attempts to capture the essence of semantic coercion and adapts it to the principles of the TfS research (Section 5.3).

\section{Are perception verbs motion verbs?}

Perception verbs like see and look typically profile an activity in which the agent perceives and/or categorizes entities and events visually. Several observations are echoed in the literature that these verbs also encode meanings of Motion. The basic assumption behind these proposals is that verbs that are used in the same syntactic frame tend to similar meanings.

According to Gruber (1967, p. 940) for instance, the extent that verbs of perception occur in the same syntactic frames as typical motion verbs suggests that the grammar treats perception verbs as 'motional'. To justify his conclusion, Gruber (1967, p. 937) provides different contextual uses of the verb see:

(2) (a) Bill thought he could see into the room. ${ }^{7}$

(b) It is easy to see through this glass.

(c) The baby saw over the rim of the nest.

(d) Using X-ray vision, Superman saw behind the tree.

The verb see in the above examples is used intransitively and is followed by prepositions as different as into, through, over, and behind. Gruber points out that these same prepositions also would occur with typical motion verbs describing acts of 'flying' or 'running' for instance:

(3) The frightened bird flewinto/over/through/behind the bush.

Crucially, Gruber (1967) claims that a sentence like John sees a cat is a metaphorical extension of a clause like John goes to a cat. This similarity in the underlying structure is no different from John sees across the room to John goes across the room, which in turn may be paraphrased as John's gaze goes across the room. He argues that if the paraphrase of [motion verb + across] is acceptable then it should be equally acceptable to say John's gaze goes to the cat is semantically close to John sees the cat (1967, p. 943). Based on these observations, Gruber concludes in utterances like John sees a cat, a schematic meaning of TO is incorporated into the semantics of see even when it is not overtly lexicalized (1967, p. 938).

Furthermore, Gruber (1967) observes a division of labour in the syntactic behavior of these perception verbs. Notably, while see usually teams up with prepositions that have an underlying meaning 'reaching a goal', the verb look teams up with prepositions whose underlying meaning is 'measuring out' distance. The following examples taken from Gruber (1967, pp. 943-944) illustrate his point:

(4) (a) run toward the tree

(b) *saw toward the house

(c) look toward the house

(d) *look to the tree

(e) look toward the well

According to Gruber, the verb see only accepts those prepositions that have an underlying meaning of TO and not TOWARD. The verb look, however, only accepts prepositions with an underlying meaning TOWARD. In this respect, Gruber argues that look complements see in the expression of motional meanings in English (1967, p. 42). ${ }^{8}$

former - an account that Ziegeler claims "is no different from a form of conversational inferencing" (2007, p.

1003 ).

${ }^{7}$ Italics are not in original. 


\section{1. 'Look', 'see', and motion: Evidence from developmental psychology}

Following Gruber's (1967) analysis of the verbs see and look, Landau \&Gleitman (1985) compared the acquisition of see and look by visually-impaired children and sighted children. They claim that for sighted children as well as the visually impaired, look is 'motion toward' and see 'is motion to' and that the "concepts look and see are spatial and encode the notions of location and motion" (1985, p. 135). Interestingly, Landau \&Gleitman (1985) argue that blind children construe the world of experience through haptic modalities on the one hand, and through their intuitive knowledge of the English argument structure on the other. In their words, "where the eye is missing [...] the young learner is predisposed to consider the sentence of English in terms of a predicate-argument logic in which the verb serves as the predicate itself and the various nominal surrounding it serve as its arguments" (1985, p. 123). Since perceptual verbs behave syntactically much like verbs of physical motion in terms of the spatial prepositional phrases they allow, Landau \&Gleitman (1985, p. 128) claim that blind children learn the distinction between see and look by formulating their own theories based on argument structure. To the extent that child-directed speech is replete with [seellook + spatial particle] constructions, they further claim that blind children would eventually develop a hypothesis that is consonant with that of linguists - namely: "syntactic privileges of occurrence of verbs are intimately related to the concepts they encode" (1985, p. 141). The motional and non-motional interpretations of the verbs see and look, therefore, are "fully predictable" from the type of prepositions they tend to be associated with in the input data (1985, p. 135).

A pertinent question that emerges from Gruber's (1967) and Landau \&Gleitman's (1985) treatments of the verbs see and look is whether other perception verbs may also be classed as motion verbs. To address this point in subsequent section I seek insights from usage-based approaches to semantic analysis. ${ }^{9}$

\subsection{Perception verbs in typological research}

Gruber's (1967) proposal for the verb look and see has been echoed in typological approaches to the linguistic conceptualization of motion under the guise of fictive and factive motion (Talmy, 1996, 2000) and visual and physical paths (Slobin, 2008).

According to Talmy (2000), for instance, concatenated verbs and satellites (and/or directional/ locative phrases) are extended from concrete descriptions to the abstract and metaphorical. He points out (2000, p. 106):

[T] he intangible entity continues along its emanation path and terminates by impinging on some distal object. [...]. Specifically, the intangible entity is what movesfictivelyand is itselffictive, and its fictive motion does not depend onany factive motion by some tangible entity nor on any localized observer.

Essentially, Talmy (2000) argues that neither the figure (i.e., the entity in motion) nor the path need be physical in a motion event. Motional readings occur because spatial particles 'coerce' such readings. Talmy (1996) provides the following examplesto illustrate his point with reference to the verbs look, face, and turn:

(6) (a) I quickly looked down into the well (1996, p. 221).

(b) The cliff wall facestoward laway from the island (1996, p. 218).

(c) I slowly turned my camera /lookedtoward the door (1996, p. 218). ${ }^{10}$

According to Talmy (1996, p. 220), in (6) the moving figures evoke a LINE OF SIGHT concept. Line of sightis itself intangible and emerges "from the visual apparatus canonically located on the front of an animate or mechanical entity" (Talmy, 1996, p. 220). The line of sight then follows the lateral motion of a particular path (1996, p. 21). Building on both Gruber's (1967) and Talmy's (1996, 2000) treatment of perception verbs, Slobin (2008, p. 198) argues that constructions expressing visual paths are not the prerogatives of English but are widely found across languages.

\footnotetext{
${ }^{8}$ An anonymous reviewer has pointed quite rightfully that Van Develde (1977) has criticized Gruber's take on the verbs see and look. However, a review by John Goldsmith (1979) suggests that Van Develde's arguments falter upon closer inspection: "While most of Van Develde's specific points are well-founded, it seems to me that there is a baby which we risk tossing out along with the bathwater if Van Develde's observations are interpreted as he suggests they be" (1977, p. 347).

${ }^{9}$ It must be pointed out that perception verbs have also been investigated in Jackendoff (1983) and Gisborne (2010). These contributions are not discussed here due to space constraints and because - to a lesser or greater degree - they both reflect Gruber's main thesis. For instance, Gisborne identifies four senses to the verb see. See ${ }^{I}$ holds a 'prototypical' sense that denotes physical perception as Jane saw Peter. See has a 'gaze-reaching' sense where the physical activity of gaze reaching is expressed through a prepositional phrase as in Jane saw into the room. See involves a sense of image-forming as in Jane isseeing stars. See $e^{4}$ shows a sense of 'understanding' as in I see the problem.

${ }^{10}$ All italics in (6) are added. 
Crucially, Slobin points out that V-languages do not offer unique perception verbs that reflect their typological affiliation. In other words, V-languages do not have verbs that conflate look + exit meaningsas is typically found in expressions ofphysical motion (e.g.,entrer 'enter'/sortir 'exit' in French). ${ }^{11}$ Instead, they follow S-framed patterns in that they capitalize on "all purpose perception verbs such as "look', combined with various sorts of adjuncts (adpositional phrases and directional adverbs in both language types, plus satellites in satellite-framed languages)" (Slobin, 2008, p. 201).

Although Slobin's treatment of perception verbs was confined to the verb look, in a footnote he notes that S-languages have more verbs describing manner of looking (e.g.,peek, peep, peer, glimpse, glare, etc.) than V-languages. This statement is significant for two reasons. First, it corroborates Talmy's (2000) claim that there is a parallel between physical and visual paths in both S- and V-languages in that S-languages usually have more manner of looking verb types than V-languages do. Second, it raises the possibility that manner-saliency in S-languages is not confined to semantic domains that are typologically sensitive. Rather, even semantic domains of perception - domains that are not influenced by the conflations patterns of their linguistic affiliation - carry the overall imprint of S-framed norms (Slobin, 2008, p. 208).

To round up the review on perception verbs, theoretical arguments based on the work of Gruber (1967), supporting developmental evidence from the work of Landau \&Gleitman (1985) encourage the conclusion that perception verbs in English ought to be classed as motion verbs in directed motion contexts. This conclusion has also been echoed in typological approaches to motion verbs but with an important addition. Motion events that involve perception verbs are treated under 'fictive motion' (Talmy, 1996) or 'visual paths' (Slobin, 2008). This observation makes the following question difficult to parry: Why does typological research engage motion event conceptualization in binary terms (i.e., fictive versus factive) when this dichotomy is neither psychologically nor grammatically warranted?

We address this question further in Section 5. For now, however, we review another grey area in the categorization of motion verbs - namely: Verbs of sound-emission.

\section{Are 'sound-emission verbs' motion verbs?}

According to Levin (1993), speakers of English know - among other things - that certain English verbs manifest EXTENDED meanings (or senses). In her view, if the BASIC meaning of a verb encodes motion, then, its semantic interpretation would not be affected by adjoining constituents in the clause. However, if a verb's basic meaning changes because of other constituent in the clause, then the newly acquired meaning is said to be an EXTENSION from the basic meaning. To illustrate this point, consider the verbs run and whistle in the following extracts. They show that the omission of the locative expressions associated with these verbs suggests that motion meanings are basic in the case of (7) but extended in the case of (8a), where the locative-less (8b) is marked with \# because it is semantically anomalous:

(7) (a) The man ran into the room. (Levin, 1993, p. 15)

(b) The man ran.

(8) (a) The bullet whistled through the window. (Levin, 1993, p. 15)

(b) \# The bullet whistled.

According to Levin (1993) neither run nor whistle are inherently directional. Yet, both verbs can be used as verbs of directed motion in the presence of a directional preposition. In The bullet whistledthroughthewindow andThe man ran into the room, the verbs run and whistle seem to share some colligational properties, and hence, a shared reading of directed motion sense.In line with Gruber (1967) and Landau \&Gleitman (1985), Levin (1993) observes that verbs whose extended senses are 'motional' must be classed as motion verbs since they show the complement-taking properties of verbs of motion which is only available in the presence of a directional phrase. Unlike Gruber (1967) however, Levin argues that native speakers have a solid appreciation of the interaction between semantic meaning and their various syntactic distributions, so much so that their "ability to make subtle judgments about possible and actual verbs and their properties makes it unlikely that all a speaker knows about a verb is indicated in its lexical entry" (Levin, 1993, p. 4).

\footnotetext{
${ }^{11}$ However, Slobin also points out that Toba, a Guaykuruan language of Argentina (reported in Klein 1981), "has a set of vision verbs that, like other path verbs, are inherently marked for directionality, e.g., lye 'look inward' and sa:t 'look up at something moving' (Slobin, 2008, p. 204).
} 
At this point, we have reached a reasonable conclusion that the meanings of various perception and sound-emission verbs are amenable to change due to their syntactic distribution. ${ }^{12}$ However, as Levin (1993) notes many other verbs in English exhibit similar kinds of polysemy as perception and sound-emission verbs. While it is possible to explore this point based on Levin's (1993) approach to semantic analysis, in my next section I choose to focus on the work of construction grammarians. This choice should not be understood as a preference for any of the arguments associated with each approach. Rather, we simply want to introduce a fresh perspective on the categorization of motion verbs so that we can enrich our understanding of those verbs that are capable of expressing motional meanings in English and also typologically.

Since construction grammarians are interested in explaining issues related to verb alternations - that is how similar verbs occur in different argument-structure patterns resulting in these verbs acquiring different senses (Bencini\& Goldberg, 2000, p. 642) - new insights into the behavior of motion verbs may be gained. Additionally, if it can be shown that various approaches to the classification of motion verbs agree about the fundamentals of motion verb categorization, then, even more insights can be gained in this respect.

\section{Motion verbs in Construction Grammar}

A pertinent aspect of the constructionist perspective is the observation that non-motion verbs in English are capable of acquiring motion interpretations by merely appearing in constructions that license such interpretations (Goldberg, 1995; Bencini\& Goldberg, 2000; Suttle\& Goldberg, 2011; Goldberg, 2013). Constructionsare defined as "the units of the linguistic system, accepted as convention in the speech community and entrenched as grammatical knowledge in the speaker's mind" (Ellis \& Ferreira-Junior, 2009, p. 370). According to Goldberg (1995, p. 152), constructions reflect different but common experiences. The CAUSED-MOTION construction is an abstract form that reflects one such experience. Its argument structure is presented in (11) where $\mathrm{V}$ is a non-stative verb and OBLis a directional phrase (Goldberg, 1995, p. 152):

$\begin{array}{lllll}\text { CAUSED-MOTION } & & & \\ \text { CAUSES } & \mathrm{Y} & \text { To } & \text { Move } & \mathrm{Z} \\ \text { SUB } & \mathrm{V} & \text { OBJ } & & \text { OBL } \\ \text { Pat } & \text { sneezed } & \text { the napkin } & \text { off } & \text { the table }\end{array}$

Goldberg (1995, p. 39) argues that the skeletal construction in (11) exists independent of the verbs that may occupy it. For instance, all clauses in (12) are instances of the same construction even though the main verbs that occupy them usually differ on the transitivity (e.g.,help, spray) and intransitivity (e.g.,laugh, sneeze) parameter in their basic usages (Goldberg, 1995, p. 152; italics added):

(12) (a) They laughed the poor guy out of the room.

(b) Frank sneezed the tissue off the table

(c) Mary urged Bill into the house.

(d) Sue let the water out of the bathtub

(e) Sam helped him into the car

(f) They sprayed the paint onto the wall

In this context, Bencini\& Goldberg (2000) point out that the newly acquired motion senses of the verbs sneeze and laugh as in (12a) and (12b) are not to be stipulated as part of the core meaning of these verbs. Rather, the motional meanings are constructed "on-line" as a result of the caused-motion construction. They argue it is the "types of complement configurations [that] play a crucial role in sentence interpretation, independent of the contribution of the main verb" (2000, p. 649). Of course, the argument that the caused-motion meanings are imposed by the construction does not mean that the primary senses play no part in the novel reading of the clause. As Goldberg observes "[i]n point of fact, when a verb lexically codes a particular meaning, it generally carries that meaning with it when it appears in other constructions" (2013, p. 445).

In short, what a construction like (11) does is that it adds arguments that are not necessarily predictable from the verb's primary meanings. This makes it possible for both motion and non-motion verbs to be used creatively (Goldberg, 2013, p. 453). Under the influence of the caused-motion construction, therefore, help, let, urge, sneeze, and laugh are just as much motion verbs as walk, run, and climb.

\footnotetext{
${ }^{12}$ Lynne Murphy (personal communication) rightfully points out that there seems to be a big difference between vision and sound verbs in that I look down a hole does not involve the translocation of the figure. However, in I whistle past the figure actually moves. In principle, this argument does not contradict the main point we are proposing here: In both sentences, a figure (i.e., either "I" or "my line of sight) is actually or virtually moving.

98
} 


\section{Discussion}

\subsection{Semantic coercion, plausibility, and native speaker judgment}

A key point that surfaced in the previous review is that the concatenation of both motion and non-motion verbs with path-bearing expressions sits at the heart of the phenomenon of semantic coercion for English. However, at least two arguments can be raised that this proposal is too unconstrained to serve as a framework for the investigation of the MvP in TfS.

First, according to Ziegeler (2007) several pieces of counter-evidence may be raised against the explanatory power of Goldberg's (1995) caused-motion construction. For example, although (13a) and (13b) fit within the caused-motion construction, they do not yield motional interpretations. In (13c), however, the directional semantics are coerced into the locative complement because the verb place is inherently causative:

(13) (a) Sam blinked the fork off the table.

(b) Sam sneezed the napkin on the table

(c) Sam placed the napkin on the table

According to Ziegeler (2007, p. 1007), (13a) and (13b) do not acquire a motional reading because "under normal circumstances" it is impossible to move a fork simply by blinking at it, or move a napkin to a location on a table simply by sneezing. This suggests the caused-motion construction as discussed with reference to English seems to be "limited by plausibility" in that lexical items must necessarily describe events that are 'plausible'. It transpires, therefore, that "in some cases certain lexical combinations may be anomalous, and the syntax of the construction can do nothing to render them acceptable" (Ziegeler, 2007, p. 1001).

Second, throughout this survey, we have been assuming that lexicalisation patterns reflect how speakers actually conceptualize events. ${ }^{13}$ However, according to Matsumoto (2001, p. 234; cited in Slobin, 2008, p. 204) there is no conclusive evidence to suggest that $\mathrm{V}$-language speakers treat fictive motion as if it is factive despite the fact that the grammar affords the concatenation of path phrases with perception verbs.

Slobin (2008) addresses this point. He reports that he has presented his ideas about visual and physical paths to cognitive linguists from native V-languages like French and Spanish. Their responses raised questions about the validity of equating syntactic distribution with semantic coercion in V-languages (Slobin 2008, pp. 212-213). Consequently, Slobin (2008) may be right in pointing out the universality of the use of similar linguistic frames for both fictive and factive motion. However, it seems doubtful - or at least questionable - that V-language speakers actually conceive of visual paths as physical paths, at least as far as one can tell from the limited data reported in Slobin (2008).

In brief, the coercion of non-motion verbs into the expression of motion does not result simply from a random concatenation of verbs with path-bearing phrases. It seems that extra linguistic factors like 'plausibility' and 'native speaker judgment' play a crucial role in determining whether motional readings obtain or not.

\subsection{Semantic coercion in V-framed languages}

The secondary evidence reported on here suggests that the concatenation of both motion and non-motion verbs with spatial particles are the preferred modes of expression in S-languages and that, by comparison, V-languages either have a rhetorical style that partially or hardly parallels this TfSbehavior. ${ }^{14}$ At best, this conclusion provides a partial picture about TfS habits in motion event situations. At worst, this picture may be inaccurate in that it does not explore whether semantic coercion manifests itself differently in V-languages. To argue this point further, let us consider a verb-framed language like Persian.

According to Feiz (2011), Persian has an abundance of light verb constructions (LVC). These consist of a light verb like have, give, or take and a noun, adjective, or particle. For instance, a verb like zadan 'to hit' combines with lagad 'to kick' to express the manner nuance of 'quick and brief motion'. Equally, non-motion verbs like kardan 'to do' and shodan 'to become' often combine with non-verb classes to convert a non-motion construction into a motional one in terms of both path and manner (Feiz, 2011, p. 411): ${ }^{15}$

\footnotetext{
${ }^{13}$ According to Cardini (2010) - unlike other typical V-framed languages - Italian resembles English in how it favors the use of spatial particles and manner verbs in the crossing of boundaries.

${ }^{14}$ Note that Feiz (2011) did not discuss the LVC with reference to coercion.

${ }^{15} \mathrm{We}$ remind the reader of footnote 13 implying that V-languages may well have perception verbs that conflate the meaning of looking with its manner and path.
} 
(14) (a) door shodan 'distance' (distant becoming)

(b) Nazdikshodan 'approach' (close becoming)

(c) Bolandkardan 'raise, pick up' (high doing)

(d) Derazkardan 'extend' (long doing)

While the examples in (14) do not indicate whether the LVC expresses a change of location or a change of stateFeiz concludes that "what is clear is the concept of motion is not lexically coded within either of the elements of the LVCs" but rather "it is the overall semantics of LVC that carries a sense of motion" (2011, p. 411). It transpires, therefore, that the LVC is pervasive in Persian (Feiz, 2011, p. 410) so much so that native speakers of Persian prefer this type of construction to using simple motion verbs when describing motion-related events (2011, p. 410).

While more cross-typological evidence is needed before a formative conclusion is reached, the case of Persian (Feiz), Spanish, and English (Berman \&Slobin 1994) pose a direct challenge to the categorization of motion verbs in TfS. Precisely, how should the MvP be investigated? Should it be investigated at the word-class level so that only the primary meanings of verbs are used as definitional criteria or should extended meanings be considered as well if a motional construction licenses a motional interpretation? We address these questions in our next section.

\subsection{Motionization: Paving the way for semantic coercion in TfS}

Although Slobin has not discussed the implications of semantic coercion for TfS research in his earlier writings and contributions (e.g., in Slobin, 1996a, 1996b; Slobin, 2006), in "Relations between Paths of Motion and Paths of Vision" (2008) he expresses the pressing need for TfS studies to pay more attention to the similarity between visual and physical paths. Instructive as this call may be, Louhichi (2015, p. 207) observes that the study of the MvP in terms of fictive and factive seems to cement a borderline in the classification of motion verbs that is neither grammatically nor psychologically warranted. He points out that Talmy's (1996) binary distinction between fictive and factive motion is valid for semantic analysis because it shows how native speakers of English use similar linguistic expressions to meet TfS speaking demands. However, he argues "it is important not to confuse descriptive adequacy with the psychological reality of the 'physical' and the 'abstract' in TfS" (2015: 191). When speakers are in a TfS mode, there is no indication that they produce and comprehend constructions like "lookdown a hole' differently from 'climbup a tree' nor 'push a dog down a river' from 'smell a frog out of a hole' (Louhichi, 2015, p. 191). He concludes, in all these TfS situations, speakers seem to engage in a dynamic process that reflect their ability to MOTIONIZEevents according to their L1 linguistic affordances. Accordingly, when motionizing events, native speakers of English instantiate an abstract schema $\mathrm{M}_{\text {-ized }}[\mathrm{V}]$ to describe one or all of the following TfS situations:

i. When speakers combine semantically weak verbs like be and set with spatial particles to give an overall sense of directed motion as in (15a) and (15b):

(15) (a) During the night, the little frog thought "that twat didn't put the lid on!" Bag this! Am off. (Louhichi, 2015, p. 128)

(b) They [the boy and the frog] set offinto the woods. (Louhichi, 2015, p. 134)

ii. When speakers fine-tune meanings of directed motion in verbs whose primary meanings already conflate both manner and path as is the case of climb in (16a) and fall (16b):

(16) (a) So, he climbed upon the rock, peeringover some of the trees. (Louhichi, 2015, p. 123)

(b) He fell down, off the branch. (Louhichi, 2015, p. 175)

iii. When speakers combine perception and sound-emission verbs with path-bearing phrases as is the case of lookand shout in (17):

(17) The boy finds a little hole. He looks down the hole, and, he shoutsdown the hole.

(Louhichi, 2015, p. 191)

The schema $\mathrm{M}_{\text {-ized }}[\mathrm{V}]$ is abstract and consists of two main elements. First a [V]-frame that houses a predicate that is unspecified with respect to motional meanings. This relative freedom licenses the recruitment of verbs whose basic meaning is neutral (e.g.,get, be) motional (e.g.,run, climb) or non-motional (e.g.,look, smell). Second, the tag ' $\mathrm{M}_{\text {-ized' }}$ ' (i.e., short for motionized) reflects the exigencies of the two constraints discussed in sections (5.1) and (5.2) and reproduced here as follows:

Constraint 1: Plausibility and native speaker judgment constraints

Unless the extra-linguistic information of 'plausibility' and 'native speaker judgment' are factored for, a motional reading does not obtain even if a verb is used with a spatial particle (i.e., as is the case of French discussed in 5.1).

Constraint 2: $M_{\text {-ized }}[V]$ schema is instantiated differently in different $V$ - and S-languages

This constraint dictates that an English $\mathrm{M}_{\text {-ized }}[\mathrm{V}]$ is instantiated differently than a Farsi $\mathrm{M}_{\text {-ized }}[\mathrm{V}]$. In the former case, the schema is represented by the surface form [Verb + path-bearing phrase] while in the latter case, it is represented by the surface form [Nouns /adjectives/ particles + light verbs]. 
Motionization also boasts the ability to accommodate definitional issues related to satellites as opposed to prepositions in the investigations of the MvP.For instance, Ibarretxe-Antuñano (2017, p. 19) observes that several scholars (e.g., Filippovic, 2007, Beavers et al. 2010, and Croft et al. 2010) have'expanded' the notion of satellites to include prepositions and prepositional phrases. In her opinion, while it is true that Talmy's definition of satellites is problematic, "if one admits prepositions as satellites," then "the category becomes so wide that it lacks any explanatory power," and by extension, it becomes impossible to maintain a clear difference in the lexicalization patterns between V- and S- languages(2017, p. 19). She states:

[T] he notion of satellite has been problematic since its inception. The concept seemed to work fine for a while to describe English particles or Russian prefixes, but the more languages studied and the more fine-grained the studies, the clearer it became that the notion of satellite needed to be revised. It is not clear yet how and what to make of a satellite.

In Talmy's defence, Louhichi reports that Talmy (1985) has cautioned against treating satellites as a syntactic category in its own right. Instead, they should be investigated"as a group of path particles that perform a certain semantic function in the description of a motion event in the languages that have them" (cited in Louhichi, 2015: 54). Motionization - a framework that takes semantic coercion as its basic tenet - overlooks definitional issues between satellites, prespositions, and light verb constructions. The essence of semantic coercion does not lie in the category but in $\mathrm{M}_{\text {-ized }}[\mathrm{V}]$ as a TfS contruction .

\section{Conclusion}

The interdisciplinary evidence reviewed in this paper suggests semantic coercion merits more attention in TfS than it currently receives. The theoretical construct motionization (Louhichi, 2015) embraces coercion and is here offered as a first attempt at studying the MvP under a single unified framework. It is broad enough to allow for both fictive and factive motion to be concomitantly investigated. Yet, it is specific enough to respond to the exigencies of semantic coercion however it manifests itself across languages and typologies. Whether motionization as a framework proves valid, partially valid or not valid at all, remains to be seen. What seems to be valid though, is that unless S-type motionized constructionsare compared to V-type motionized constructions, TfS research may not achieve the descriptive and explanatory adequacy it has been aiming for over the last two decades.

\section{References}

Bencini, G. M. L., \& A. E., Goldberg. (2000). The contribution of argument structure constructions to sentence meaning.Journal of Memory and Language, 43, 640-651.

Berman,R.A., \&Slobin, D.I. (Eds.). (1994). Relating Events in Narrative: ACrosslinguisticDevelopmental Study. Erlbaum: Hillsdale, NJ.

Caballero, R. (2007). Manner-of-motion verbs in wine description. Journal ofPragmatics, 39, 2095-2114.

Cardini, F.E.(2010). Evidence against Whorfian effects in motion conceptualisation.JournalofPragmatics, 42, 14421459.

Ellis,N. C.,\&Ellis, F.F.J.(2009). Construction learning as a function offrequency, frequencydistribution, and function. The Modern Language Journal, 93, 370-385.

Evans, V., \& Green, M.(2006). Cognitive linguistics: An introduction. Edinburgh: EdinburghUniversity Press.

Goldberg, A. E. (1995). Constructions: A construction grammar approach to argument structure. Chicago: The University of Chicago Press.

Gisborne, N. (2010). The event structure of perception verbs. Oxford and NewYork: Oxford University Press.

Gruber, J. S. (1967). Look and see. Language,43, 937-947.

Ibarretxe-Antuñano, I.(2004). Motion events in Basque narratives. In S. Strömqvist\& L., Verhoeven(Eds.),Relating events in narrative, typological and contextual perspectives, vol. 2, (pp. 89-112). Hillsdale, NJ: Erlbaum.

Ibarretxe-Antuñano, I.(2015). Going beyond motion event typology: The case ofBasque as a verb-framed language. Folia Linguist, 49(2), 307-352.

Ibarretxe-Antuñano, I. (2017). Introduction, Motion and semantic typology: A hot old topic with exciting caveats. In I. Ibarretxe-Antuñano (Ed.), Motion and space across languages (pp. 13-36). Amsterdam/Philadelphia: John Benjamins Publishing Company.

Jackendoff, R. (1983). Semantics and cognition. Michigan: MIT Press.

Landau,Barbara\&LilaR.Gleitman. (1985). Language and experience: Evidencefromtheblindchild. Cambridge, MA: Harvard University Press.

Levin, B. (1993). English verb classes andalternations. Chicago: The University ofChicagoPress. 
Louhichi, Imed. (2015). The 'Motionisation' of verbs: A contrastive study of thinking-for-speaking in English and Tunisian Arabic (Unpublished doctoral dissertation). Brighton: University of Sussex.

Mayer, M.(1969). Frog, where are you?New York: Dial Books.

Pourcel, S. (2009). Relativisitic application of thinking for speaking. In G. Jiansheng, E.Lieven, N. Budwig,S. ErvinTripp,K. Nakamura\& Ş.Özçalişkan(Eds.), Crosslinguistic approaches to the psychology of language: Research in the tradition of Daan Issaac Slobin (pp. 493-504). Hove: Psychology Press.

Slobin, D. I.(1987). Thinking for speaking. Proceedings of the $13^{\text {th }}$ AnnualMeeting of the Berkeley Linguistic Society, $13,435-444$.

Slobin, Dan I. (1996b). Two ways to travel: Verbs of motion in English and Spanish. In M.Shibatani \& S. A. Thompson (Eds.), Grammatical constructions:Their form and meaning (pp. 195-220). Oxford:Oxford University Press.

Slobin, D. I. (1996a). From "thought and language" to "thinking for speaking". In J.J.Gumperz\&S.C.Levinson(Eds.), Rethinking linguistic relativity, (pp. 195-220). Cambridge: Cambridge University Press.

Slobin, D. I. (2004). The many ways to search for a frog. InS. Strömqvist\&L.Verhoeven(Eds.),Relating events in narrative: Typological and contextual perspectives, vol. 2 (pp. 219-258). Hillsdale, NJ: Erlbaum.

Slobin, D. I. (2006). What makes manner of motion salient? Explorations in linguistic typology, discourse and cognition. In M. Hickman \& S. Roberts (Eds.),Space in languages: Linguistics Systems, and Cognitive Categories (pp. 59-81). Amsterdam/Philadelphia: John Benjamins.

Slobin, D. I. (2008). Relations between paths of motion and paths of vision: A crosslinguisticand developmental exploration. In V.C.M.Gathercole(Ed.), Routes to language: Studies in honor of Melissa Bowerman (pp. 197222). Hove: Psychology Press.

Suttle,L.,\&Goldberg, A.E.(2011). The partial productivity of construction as induction.Linguist,49, 1237-1269.

Talmy, L. (1985). Lexicalization patterns: Semantic structure in lexical forms. In T.Shopen(Ed.),Language typology and syntactic description, vol. III: Grammatical categories and the lexicon (pp. 56-149). Cambridge: Cambridge University Press.

Talmy, L. (1996). Fictive motion in language and "ception". In M.Shibatini\&S. A.,Thompson(Eds.), Language and space (pp. 1-276). Cambridge, MA: MIT Press.

Talmy, L. (2000). Toward a Cognitive Semantics, vol. 2. Cambridge, MA: MIT Press.

Ziegeler, D.(2007). A word of caution on coercion. Journal of Pragmatics, 39, 990-1028.

Zlatev, J., \&Yankglang, P.(2004). A third way to travel: The place of Thai in motionTypology. In S.Strömqvist\&L.Verhoeven(Eds.),Relating events in narrative: Typological and contextual perspectives, vol. 2 (pp. 159-190).Hillsdale, NJ:Erlbaum. 